\title{
U, THE SIXTH WAVE OF THE ELECTROCARDIOGRAM
}

\author{
BY \\ CORNELIO PAPP \\ From the Cardiac Department of the London Hospital \\ Received August 17, 1939
}

Einthoven (1906) was the first to mention the sixth or $U$ wave of the electrocardiogram. In 1912 he found it in half the records he examined for this purpose. Lewis and Gilder (1912) first gave statistics of the U wave in healthy people, finding it in 90 per cent., most often in lead II, and of an average height of $0.16 \mathrm{~mm}$. They saw it as a sharp peak immediately after $\mathrm{T}$ or as a shallow bending of the whole T-P period. Hering (1913) thought it was aortic and not cardiac in origin.

There are references in various textbooks. Hoffman (1914) described it as "produced by the passive movements of the heart ... starting after the closure of the semilunar valves . . . belonging to the diastole." Kahn (1914) also thought it important in proving that the end of the electrical activity of the heart is not limited by the $T$ wave. It is mentioned as frequently present (Wiggers, 1923) ; as of unknown meaning (Lewis, 1925) ; as of uncertain origin (Reid, 1928) ; and as of doubtful relationship to ventricular systole (Wenckebach and Winterberg, 1927). In the second edition of his book Pardee (1924) says : "A broad low wave, called $U$, is sometimes observed following $T$. It is probably not due to the heart at all, but is caused by the great vessels." There is no reference to it in his third edition (1933) or in the books of Weber (1926) or of Boden (1932).

Hoogewerf (1929), finding it in athletes, thought it might indicate a strong heart ; and Csinady (1930) had a similar impression. Maekawa (1931) studied the electrical events on the muscle strip of the frog's heart and registered the $\mathrm{U}$ wave. In human records he separated two types (already mentioned by Lewis and Gilder), of which the short and peak type was held to represent the physiological and the shallow and long type the pathological form. He saw a certain relation between the height of $T$ and of $U$. Trendelenburg (1934) in various chest leads from normal persons found $U$ always present in one or more leads. Though admittedly a normal wave, "it can become more apparent in cardiac hypertrophy." Gross (1934) agreed that it is a normal event and denied the interdependence of $T$ and $U$. Hinden (1935) was one of the first to analyse a series of records showing large $U$ waves. In his paper, with figures from the Heart Hospital and the London Hospital, he allowed no distinction in the 
significance of the two forms mentioned by Maekawa, for both were found equally in healthy and in diseased subjects. Herles (1934) found large U waves in some records taken from dying human hearts, though his two figures are scarcely conclusive. Holzmann and Wuhrmann (1936) noted increased size of the $U$ wave (as well as of $P$ and $T$ waves) after exertion. In several cases of Blumberger (1937) it was absent before exertion but appeared after it. Schulz (1938) suggested that a failure of $U$ to appear after exertion might indicate a pathological "deactivation" (inactivationsprozess) in the heart. Székely (1938) found it largest in a chest lead; there was no direct relation between hypertension and the $U$ wave, but in coronary sclerosis it was less common than in other heart diseases or in healthy people.

Since this investigation was completed, a new and important article on the U wave has appeared, that of Nahum and Hoff (1939). Investigating the supernormal period of recovery in the mammalian heart, they found that the $\mathrm{U}$ wave coincided with it. While in tachycardia the period fell at the end of $\mathrm{T}$, in bradycardia it appeared closely after $\mathrm{T}$ and became visible. In 75 per cent. of 151 normal human records and in 40 per cent. of 90 pathological records, a $\mathrm{U}$ wave of at least $0.25 \mathrm{~mm}$. was found, using lead IV R. Its maximal height was $1.5 \mathrm{~mm}$. and the average duration $0.20 \mathrm{sec}$. In pathological conditions it can be fused with $T$ or can be inverted. The inverted $U$ may be the only electrocardiographic sign of a damaged heart; it was seen in coronary, rheumatic, hypertensive, and pulmonary heart disease, and was thought to be due to metabolic changes in the heart muscle, reflected in an altered shape of the after-potential. The frequent coincidence of extrasystoles with the $U$ wave was considered a further proof that it is the electrical expression of the period of supernormal excitability.

\section{METHOD OF INVESTIGATION}

From a large number of electrocardiograms those were selected in which $U$ could be identified in the limb leads. In about 70 per cent. of normal cardiograms a deflection could be found in one or more leads on the diastolic line, but often so small that neither its dimension nor its duration could be measured. For this reason $0.5 \mathrm{~mm}$. was chosen as the limit in height for this study. Using this rather strict criterion, the electrocardiograms showing $U$ waves were reduced to about 5 per cent. of 2000 suitable consecutive records, excluding those with auricular fibrillation, flutter, and tachycardia above 110 a minute, in which conditions it proved impossible to identify the $U$ wave.

The patients providing these selected records were studied with regard to the rate of the pulse, blood pressure, clinical diagnosis, and radiological appearances. The electrocardiogram was examined as to the systolic period and the distribution of the $U$ wave in the different limb leads in health and disease. Investigations were also made on the action of digitalis and quinidine on the U wave.

The physiological $U$ wave changes were watched in healthy men under various conditions. The limb leads proved unsuitable for studying the slight 
changes that might appear under respiratory or effort tests, carotid compression, atropin, or amyl nitrite. Chest leads, especially the IV R standard lead, were used for this purpose. After trying the exploring (proximal) electrode on various sites on the chest wall-left pectoral (Wood and Selzer, 1939), base, and on or external to or internal to the apex-and the indifferent (distal) electrode on the back or on the left leg, it was found that the largest $U$ wave deflections were obtained by lead IV, R.

\section{The U WaVe in Health}

The normal $U$ wave is found at any age from 16 to 75 years, and sex seems to make no difference. At what age the wave appears is undecided. Papers on the electrocardiograms of normal children (Krumbhaar and Jenks, 1917 ; Seham, 1921 ; Lincoln and Nicolson, 1928 ; Bruce, 1931) do not mention it nor contain records showing it.

The height of the normal $U$ wave in limb leads is from 0.10 to $1 \mathrm{~mm}$., and its duration is from $0 \cdot 16$ to $0.24 \mathrm{sec}$. The shape of the wave-often only a slight hump of the diastolic line-and its variation in size and form in the same record make an exact description difficult. The normal $U$ wave in lead IV $R$ is

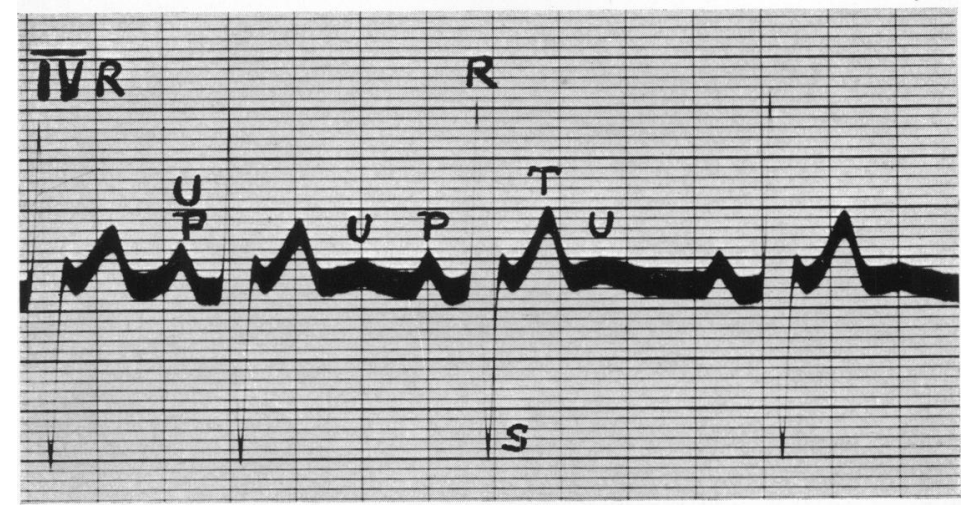

FIG. 1.-Electrocardiogram showing fusion of $U$ and $P$ in tachycardia ; with slowing of the heart rate they become dissociated.

upright, 0.5 to $2 \mathrm{~mm}$. in height, with a duration of 0.18 to $0.24 \mathrm{sec}$, and begins before or closely after the end of $\mathrm{T}$. Its visibility is notably influenced by the heart rate. In tachycardia (over 105-110), when $T$ and the following $P$ are close together, $\mathrm{U}$ becomes hidden in $\mathrm{P}$. Indeed, the higher $\mathrm{P}$ in tachycardia may be reckoned as partly due to the fusion of $P$ and $U$ (Fig. 1). The first $P$ of this record is $3 \mathrm{~mm}$. high, the others are only $2 \mathrm{~mm}$.

In bradycardia (under 60), the R-T period increases in duration. While with a rate of 80-90 the duration of the whole ventricular complex (from start of $Q$ to the end of $T$ ) has an average value of $0.35 \mathrm{sec}$., with a rate of 52 the R-T period extends to $0.46 \mathrm{sec}$. (Pardee, 1933). In one of our healthy students, with a bradycardia of 54 , the duration of the ventricular complex (Q-T) is generally $0.44 \mathrm{sec}$. The $U$ wave appears on the record as a hump on the descending 
branch of $\mathrm{T}$ (Fig. 2, A and C). This deformity of $\mathrm{T}$ is recognized as $\mathrm{U}$ when the duration of the systolic period $(\mathrm{Q}-\mathrm{T})$ decreases, as happens in the slight tachycardia following effort (Fig. 2 B). The maximal duration of the ventricular complex at which $U$ can appear as an independent wave rising from the isoelectric line seems to be $0.40 \mathrm{sec}$. With a duration of $0.40 \mathrm{sec}$., $U$ can be

A

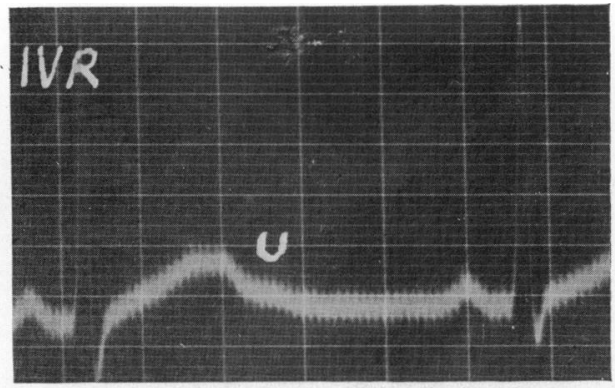

B
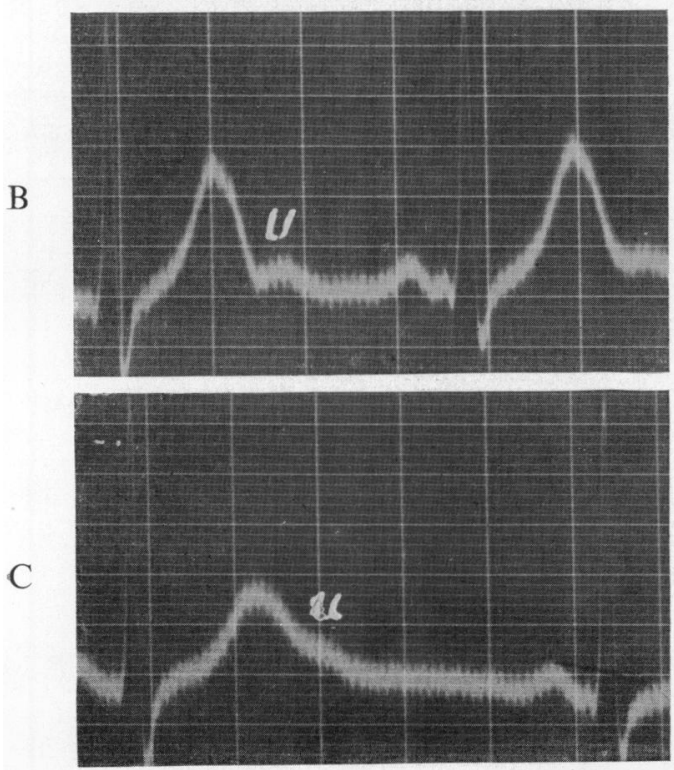

FIG. 2.-(A) Fusion of $U$ and $T$ in bradycardia, 54 a minute : (B) separation of $U$ from $T$ in tachycardia from exertion, 76 a minute : and $(C)$ return to fusion of $U$ with $T$ three

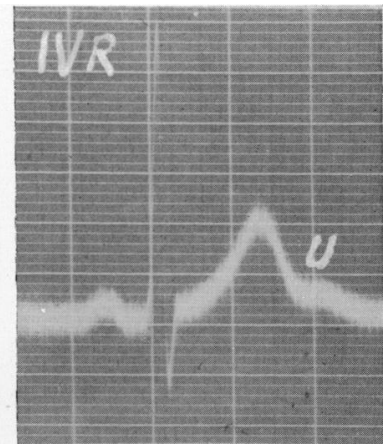

A

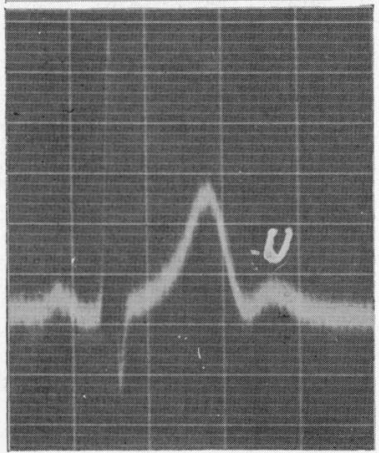

B minutes later.

FIG. 3.-Separation of $U$ and $T$ by holding the breath (B), without change in rate.

partially hidden in $\mathrm{T}$ yet appear as an independent and larger wave at the end of a forced apnœa (held breath) (Fig. 3 B).

The fusion of $U$ with $P$ in cases of tachycardia or with $T$ when the ventricular complex becomes prolonged prompts the question whether exact time relations between $R$ and $U$ can be established. This can only be answered by studying records in which exact measurements are possible. It is only when $U$ has a sudden onset or is peak-shaped or finishes abruptly on the isoelectric line that $R$ and $U$ time relations can be at all exactly established. Two of the experimental records proved suitable. In one, in which the $R-T$ interval varied 
between 0.36 and $0.43 \mathrm{sec}$. owing to the change in rate with respiration or exercise, the interval $R$ to $U$ peak showed the remarkable stability of 0.42 to 0.44 sec. In the other, the R-U (end) interval of $0.56 \mathrm{sec}$. remained nearly unchanged when the rate from 52 rose to 72 , although the R-T (end) interval decreased from 0.46 to $0.36 \mathrm{sec}$. Thus the stability of the $R-U$ allows us to consider $U$ as independent of $T$, to establish certain relations between QRS and $U$, and to deny any regular time relation between $T$ and $U$. Respiratory changes of $U$ are seen in sinus arrhythmia ; during inspiration it increases in height and becomes shorter in time, and during expiration it becomes flatter and its duration is prolonged. In such variations one can find in the same record the two types of wave described by Lewis and Gilder (1912) (see Fig. 4). Thus the statement

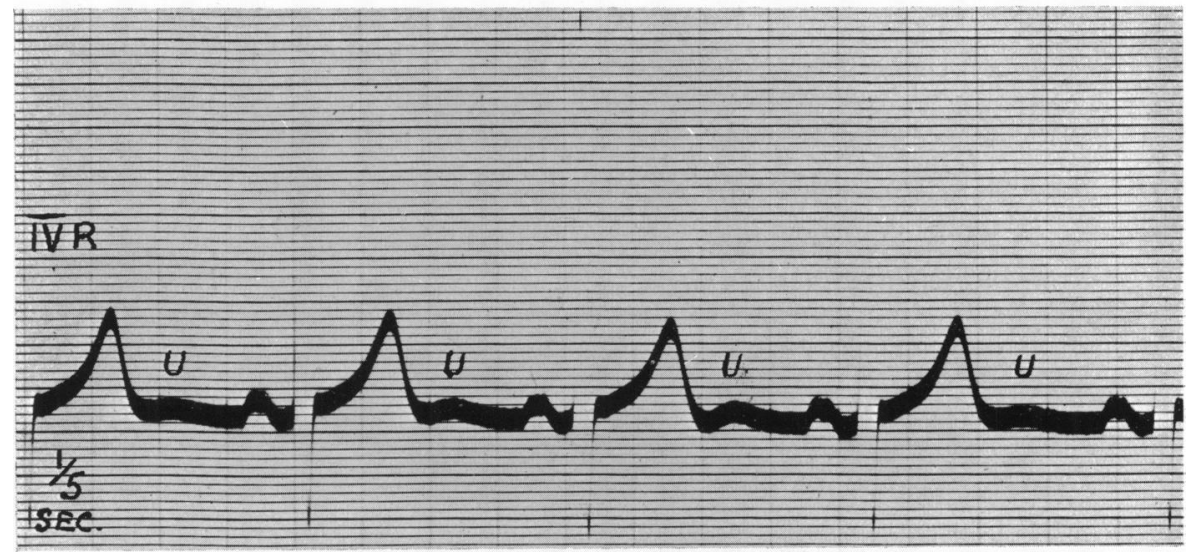

FIG. 4.-Respiratory variations of $U$. It is sharper and shorter during inspiration.

made by Maekawa (1931) and denied by Hinden (1935), that the short and peaked $U$ is the normal and the large and flat is the pathological $U$ wave, is unfounded.

\section{Further Observations on Healthy Men}

The standard lead IV $R$ was used and the experimental results are given in Table I. Nearly constant experimental results have been obtained on exercise

TABLE I

Changes in the Size of the U Wave under Various Conditions in Five Healthy YOUNG MEN

\begin{tabular}{|c|c|c|c|c|c|}
\hline $\begin{array}{c}\text { On } \\
\text { Exercise }\end{array}$ & $\begin{array}{l}\text { After } \\
3 \text { minutes }\end{array}$ & $\begin{array}{c}\text { Normal } \\
\text { Respiration }\end{array}$ & $\begin{array}{l}\text { Deep } \\
\text { Breath }\end{array}$ & $\begin{array}{c}\text { Breath } \\
\text { Held }\end{array}$ & $\begin{array}{c}\text { Carotid } \\
\text { Compression }\end{array}$ \\
\hline $\begin{array}{c}+ \\
+ \\
+ \\
++ \\
++\end{array}$ & $\begin{array}{c}+ \\
+ \\
+ \\
+ \\
+\end{array}$ & $\begin{array}{l}\mathbf{R} \\
\mathbf{O} \\
\mathbf{O} \\
\mathbf{O} \\
\mathbf{R}\end{array}$ & $\begin{array}{l}\frac{0}{0} \\
\frac{0}{0}\end{array}$ & $\begin{array}{c}\mathrm{O} \\
++ \\
+ \\
+ \\
+\end{array}$ & $\begin{array}{c}\overline{-} \\
\overline{\mathbf{O}} \\
-- \\
+\end{array}$ \\
\hline
\end{tabular}


(20 knee-bendings), both immediately after and three minutes later. The increase in the size of $U$ on effort does not seem to be due to tachycardia. It remains increased after the tachycardia has ceased and can also be found where there is little or no acceleration after effort. The two cases which showed diminution of $U$ on deep breathing showed the same after carotid compression ; in one of them $U$ disappeared, in the other it diminished.

Both methods, especially the latter, produce vagal excitation. The vagal release by atropin (1/50 grain, i.e. $1.3 \mathrm{mg}$., subcutaneously) had no effect on the $\mathrm{U}$ wave in the four observations made. Amyl nitrite was administered in all five cases, but the resultant tachycardia nullified the observations on the $U$ wave. Forced apnca produced in three of five cases an enlargement of the $\mathrm{U}$ wave, most noticeable when the subject could no longer hold his breath.

Increase in height of $U$ is almost always accompanied by increase in the
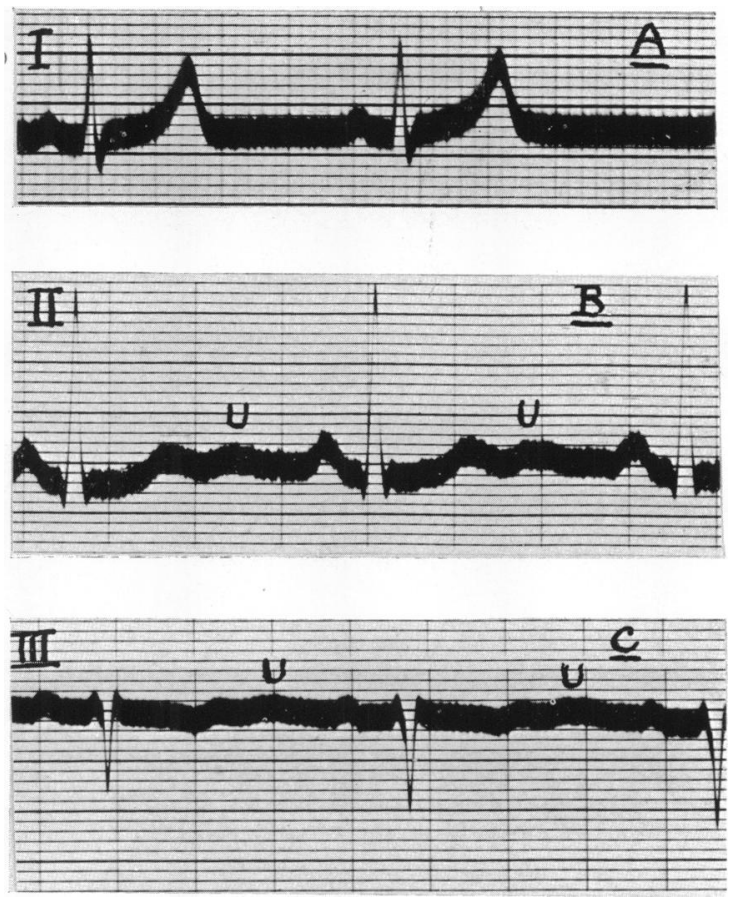

FIG. 5.-Relative independence of size of $U$ and T. Records from three healthy men ; (A)

$\mathrm{U}$ absent with large $\mathrm{T}$; (B) $\mathrm{U}$ almost as large as $\mathrm{T}$; (C) $\mathrm{U}$ upright after diphasic $\mathrm{T}$.

height of $T$. The $T$ wave not only enlarges, but changes its shape and becomes rather pointed, especially after effort. Yet in normal conditions big $U$ waves are often observed following small or even inverted $\mathrm{T}$ waves (Fig. 5).

\section{The U Wave in Disease \\ A. The Upright $U$ Wave}

One hundred consecutive records of patients with heart disease were examined, records in which the $U$ wave was $0.5 \mathrm{~mm}$. high or more in at least one of the three standard limb leads. 
1. Heart Rate.-This has little importance except that $U$ is scarcely to be identified at rates above 110 , as shown by the following figures.

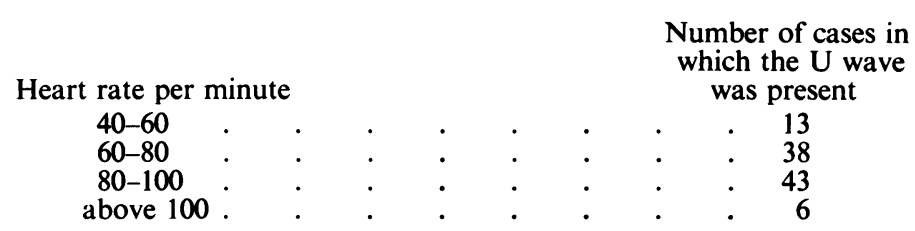

2. Systolic Blood Pressure.-The frequent incidence (47 per cent.) of hypertension among patients showing a large $U$ is evident from this table.

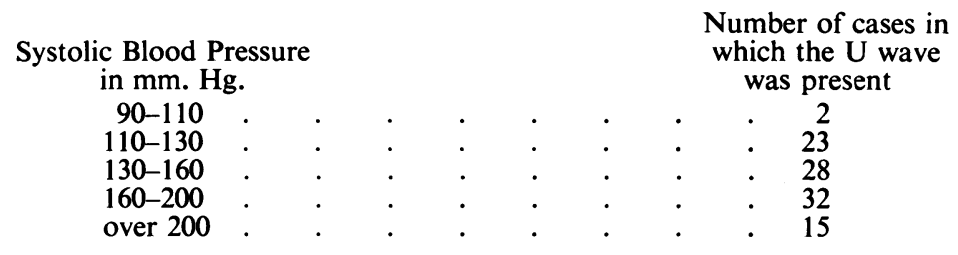

3. Clinical Diagnosis.-Hypertension in its three groupings is seen to account for no less than 37 per cent., compared with 17 per cent. without heart disease.

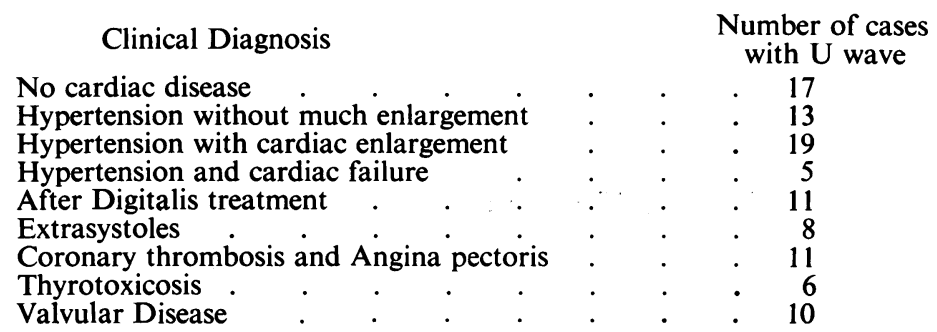

Incidentally, Spang and Korth (1939) found that 20 out of 200 thyrotoxic cases had pronounced $U$ waves in limb leads. Some relationship between the left ventricle and the $U$ wave is suggested by its frequency in conditions affecting the left ventricle, and also by the fact that lead IV R (pertaining especially to the left ventricle) is favourable for its demonstration. It was easy to find among young and athletic students many with large $U$ waves. This bears on the statements of Csinady (1930) and Hoogewerf (1929). Bramwell and Ellis's (1931) paper contains records of two long-distance runners with prominent $\mathrm{U}$ waves. Congenital heart disease seldom shows records with large $U$ waves, even where all the ventricular deflections are greatly enlarged in the right axis deviation.

Heart Failure.-Besides the five cases of hypertensive failure quoted, fifty other cases of failure with normal rhythm were examined and in three only was $U$ present before digitalis therapy. In four others in this extra series it appeared only after digitalis. In general, $U$ tends to be less frequent and smaller in heart failure (certainly left) than in its absence.

Digitalis.-In 11 cases $U$ was seen only after digitalis treatment, but in 6 of these there had been tachycardia, fibrillation, or flutter, which would have 
prevented its recognition even if present. The remaining 5 show that it may be accentuated or even produced by digitalis (Fig. 6). No effect on the $U$ wave was noticed even after prolonged administration of quinidine.

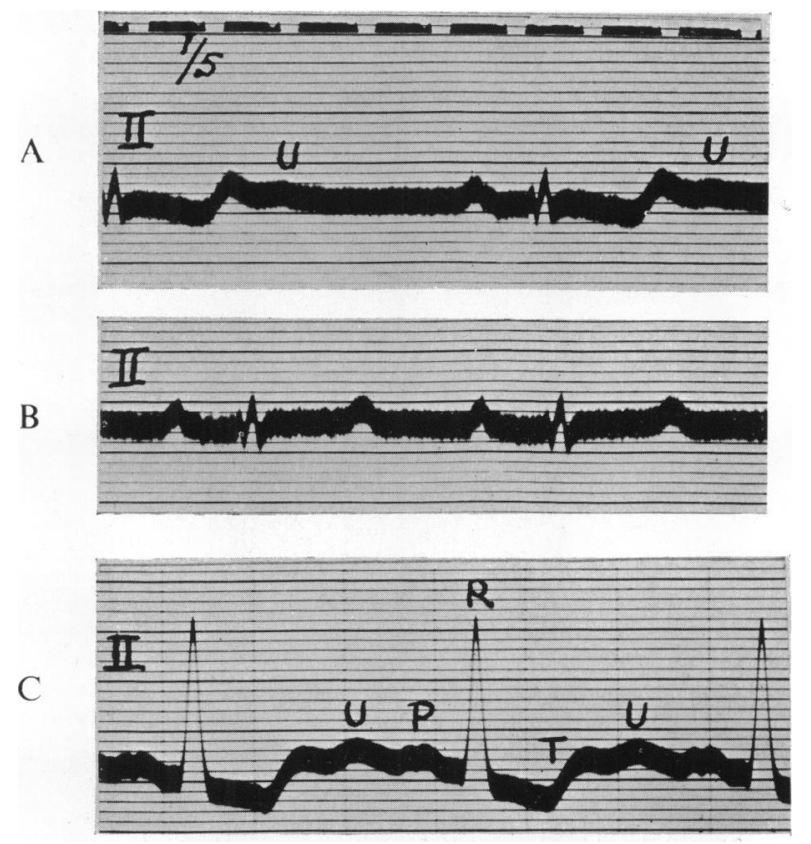

FIG. 6.-Digitalis effects. (A) The $U$ wave is well seen after full doses of digitalis ; and (B) absent four weeks after it was stopped ; (C) Very large U waves following prolonged digitalis administration.

\section{X-ray Findings.}

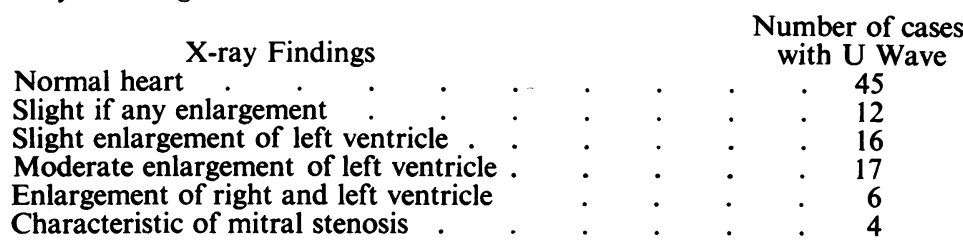

5. Electrocardiographic Findings.-In half the hundred records showing a large $U$ the electrocardiogram was normal. When abnormal, the change usually concerned the $T$ waves. In 32 with flattened or inverted $T, U$ was upright - a fact which stresses their independence in disease as already described in health.

Normal

Electrocardiogram

Left axis deviation

Right axis deviation

$T_{1}, T_{2}$ changes from Hypertension

$T_{1}, T_{2}$ changes from Coronary disease

$T_{2}, T_{3}$ changes from Coronary disease

$\mathbf{R}-\mathbf{T}$ depression (digitalis)

A-V dissociation

Number of cases with U Wave

Upright Inverted

$\begin{array}{rr}50 & 0 \\ 6 & 0 \\ 1 & 0 \\ 14 & 4 \\ 12 & 2 \\ 5 & 2 \\ 3 & 0 \\ 1 & 0\end{array}$


The systolic period R-T showed, using Pardee's table (Pardee, 1933), in 78 per cent. a normal value, in 14 per cent. slight prolongation, and in 8 per cent. distinct prolongation. Contrary to the opinion of Einthoven (1912) and Maekawa (1931), therefore, no relationship was found between the presence of $\mathrm{U}$ and the lengthening of systole.

6. Distribution of Upright $U$ in Leads I, II, and III.- $U$ appears most often in lead II, and it was present in this lead in 87 per cent. While $U$ in lead II was found equally in normal and in pathological records, the isolated appearance of $U$ in leads I or III was, with one exception, in pathological records.

Normal electrocardiogram
Left axis deviation
Right axis deviation
$\mathrm{T}_{1}, \mathrm{~T}_{2}$ changes in hypertension
$\mathrm{T}_{1}, \mathrm{~T}_{2}$ changes in coronary disease
$\mathrm{T}_{2}, \mathrm{~T}_{3}$ changes in coronary disease
$\mathrm{R}-\mathrm{T}$ depression (digitalis)

\begin{tabular}{ccccc} 
Cases & $\mathrm{U}_{1}$ & $\mathrm{U}_{2}$ & $\mathrm{U}_{1,2}$ & $\mathrm{U}_{2}{ }_{3}$ \\
55 & 1 & 44 & $8 \dagger$ & 2 \\
6 & - & 4 & $1+$ & 1 \\
2 & - & - & 2 & - \\
14 & 1 & $10^{*}$ & 2 & 1 \\
13 & 4 & $9^{*}$ & - & - \\
5 & 2 & $3^{*}$ & - & - \\
5 & 1 & $3^{*}$ & 1 & - \\
\hline 100 & 9 & 73 & 14 & 4
\end{tabular}

* Including in each case one with $\mathrm{U}_{3}$ only.

$\dagger$ Including in each case one with $U_{1}, U_{2}$, and $U_{3}$.

\section{B. The Inverted $U$ Wave}

In 8 per cent. of the series an inverted $U$ wave was seen in the limb leads, and it could always be confirmed in lead IV R. The patients concerned had coronary thrombosis (5 cases, 3 with hypertension) or hypertension alone ( 3 cases). With one exception $\mathrm{T}$ changes were always present. Three cases of coronary thrombosis were of the $T_{1}$ type, and two cases of the $T_{3}$ type (Fig. 7).

A
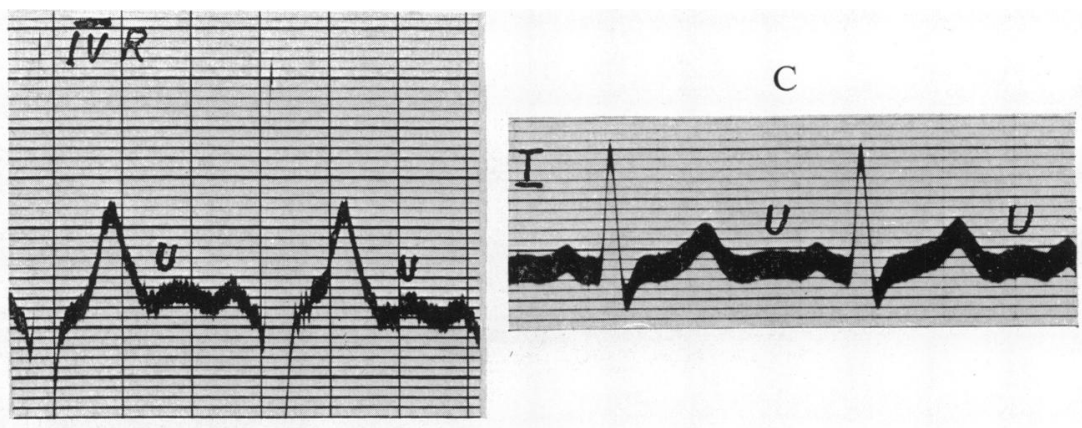

B
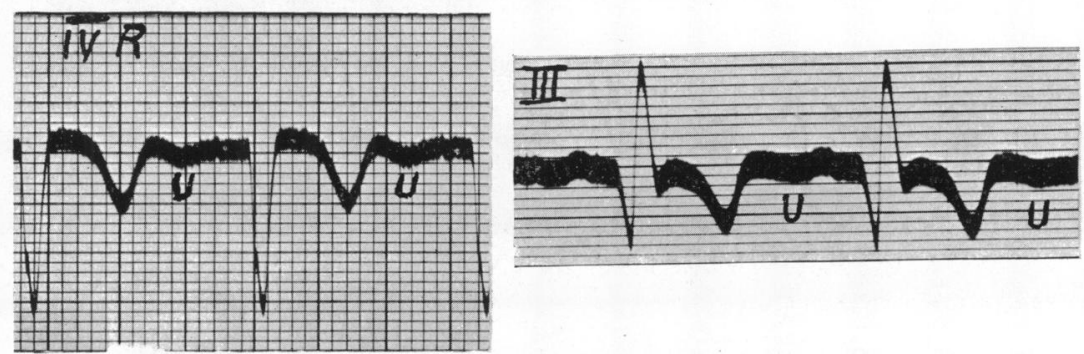

FIG. 7.-(A) Before, and (B) three weeks after coronary thrombosis, to show inversion of the $U$ wave. $T_{1}$ was also inverted (anterior infarct). $U$ is identified by measurement from $R$ or from $\mathrm{S} ;(\mathrm{C})$ three weeks after posterior coronary thrombosis in another case. 
A transition stage from upright to inverted $U$ is shown in Fig. 8, where $U$ is diphasic in IV R.

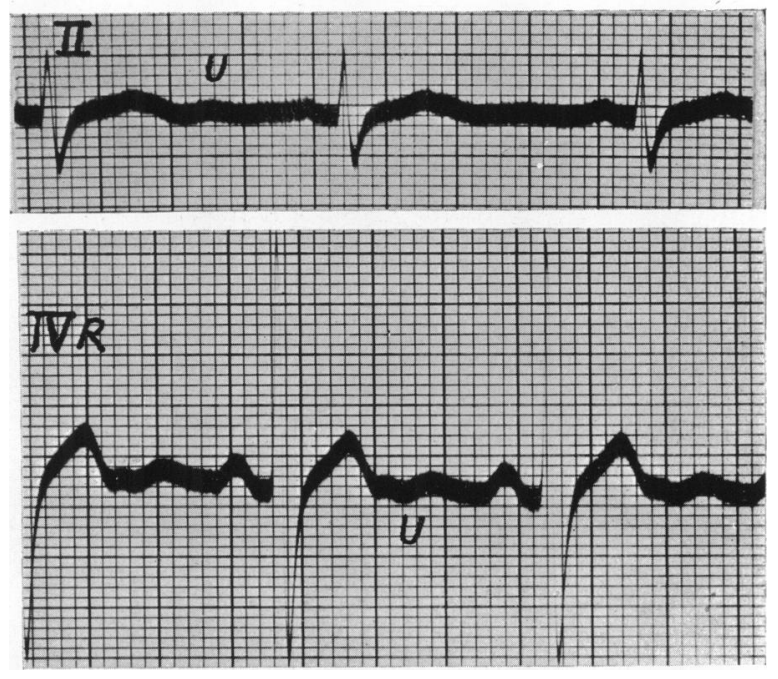

FIG. 8.-Diphasic $U$ in lead IV $R$ with upright $U$ in lead II.

Inversion of the $U$ has never been seen by me nor has it ever been reported in a normal electrocardiogram, so must be considered pathological. This new sign, not previously described except by Nahum and Hoff (1939), may become of some clinical value. It may prove the only pathological sign (Fig. 9).

\section{With Extrasystoles and Bundle Branch Block}

If ventricular extrasystoles are accompanied by a $U$ wave, this is often upright ; but where the $\mathrm{S}$ component is inverted, $U$ may be inverted. $U$ is seldom seen in pathological bundle branch block; and among 60 such cases it was only seen in four limb lead records. This rarity can scarcely be due to the long duration of the ventricular complex, for this rarely exceeds $0.40 \mathrm{sec}$., a period which would permit its recognition. In the common type of bundle branch block the $U$ wave is generally inverted in lead I and upright in lead III, following the direction of $S$ (Fig. 10). Comparing records from two patients, the one without failure showed $U$ only in left pectoral-R (Wood and Selzer, 1939), but the other with failure, using the same lead, did not. U was never seen in bundle branch block with failure.

In bundle branch block with a short P-R interval, the so-called Wolff, Parkinson, and White syndrome (1930), there may be a reversion of the short $\mathrm{P}-\mathrm{R}$ wide $\mathrm{QRS}$ complexes to normal complexes. The $\mathrm{U}$ wave, when absent in the former, may be evident in the latter (Tung, 1936 ; Fig. 8 in Wolff, Parkinson, and White, 1930).

\section{RECOGNITION OF THE U WAVE}

This may be difficult in simple bradycardia or tachycardia owing to its fusion with $\mathrm{T}$ or $\mathrm{P}$ respectively (Fig. 1, 2, \& 3). When in tachycardia the T-P 


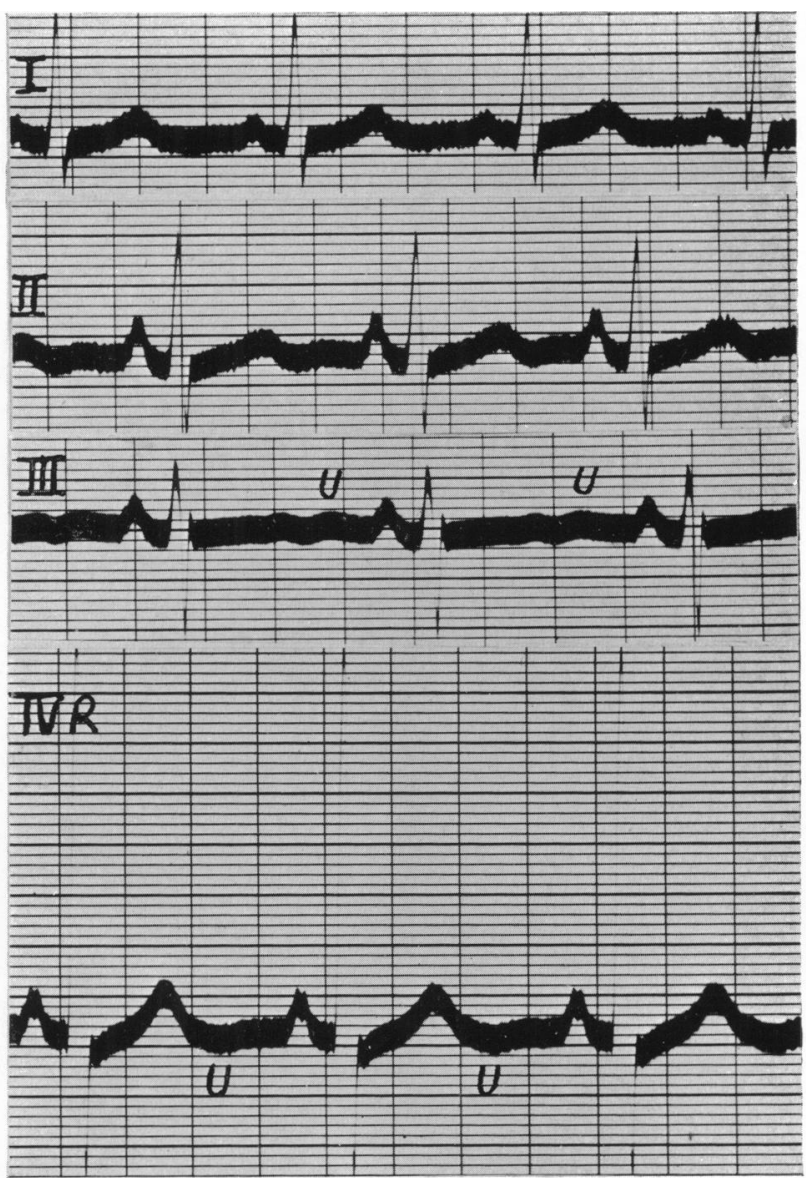

FIG. 9.- Inverted $U$ as an isolated electrocardiographic sign in lead IV R. The R-U distance in leads III and IV $R$ is the same ; from a man with hypertension and angina of effort.

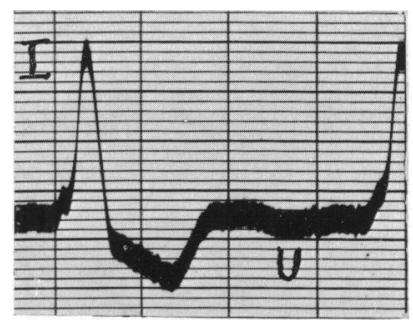

Fig. 10.-Left bundle branch block ; inversion of $\mathrm{U}$ in lead $\mathrm{I}$. 
distance has the same length as a large $U$ wave, the curve may resemble that of auricular flutter. A premature auricular beat with blocked ventricular complex may look like a $U$ wave, but there is a compensatory pause to be explained. The greatest difficulties, however, arise in the rare cases of bifid T wave. Such a wave may be followed by $U$, so that there are three upright deflections between

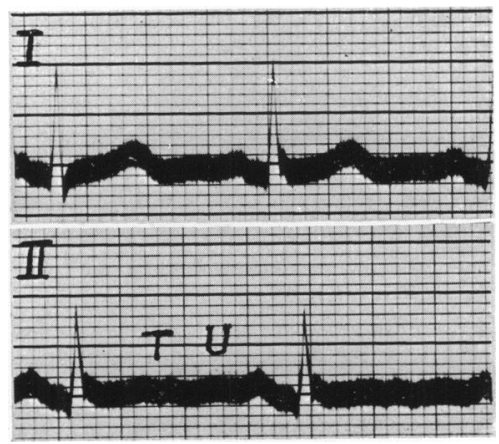

Fig. 11.--Presence of bifid $\mathrm{T}$ along with $\mathrm{U}$. The R-T distance, measured in lead I, covers $\mathrm{T}$ but not $\mathrm{U}$ in lead II.

$\mathrm{R}$ and $\mathrm{P}$ (Fig. 11). In this record, the $\mathrm{R}-\mathrm{T}$ (end) distance in lead $\mathrm{I}$, measured on lead II, shows that the second deflection after $R$ must be included as part of $T$.

\section{INTERPRETATION OF THE U WAVE}

The several hypotheses advanced to explain the $U$ wave may first be divided into the extracardiac and the cardiac.

1. Extracardiac hypotheses.-Hering (1913) viewed the U wave as the electrical expression of the aortic contraction. Lewis (1915) disagreed, finding its occurrence so long after the carotid pulse incompatible with an aortic source. Trendelenburg (1934), knowing that an electric current may be generated at the end of systole by a rapid blood flow, thought that this might account for it. All subsequent evidence has been against this view, which also may be dismissed. Similarly there is no evidence that the swing of the heart during diastole could originate such an electrical disturbance as the $U$ wave manifests.

2. Cardiac hypotheses.-The almost constant time relation with QRS, a certain but limited correspondence with the size and direction of $\mathrm{T}$, and the influence on $U$ of several factors that also affect the heart, all go to prove that the $\mathrm{U}$ wave is part of the electrical expression of cardiac activity or an immediate consequence of it. Its position on the borderline between systole and diastole raises the important question, to which of these does it belong? According to Einthoven (1912) and Maekawa (1931), the main part of the heart muscle is already in a state of relaxation when $U$ appears, but a few muscle fibres are still in contraction: it would then be the expression of a "dying away of the contraction," a systolic product though appearing early during diastole. On the other hand, Lewis and Gilder (1912), Trendelenburg (1934), and Lewis (1937) regard U as belonging to diastole. Its position in relation to the polygraphic (venous 
pulse) tracing should enable us to place it correctly in regard to the cardiac cycle. With a normal heart rate, it begins coincidently with the peak of the " $v$ " wave or somewhat later, i.e., after the opening of the A-V valves (Fig. 30, Lewis, 1925), and not with the ascending portion of " $\mathrm{v}$ " as presented in the diagram by Lewis (1925) (his Fig. 24). Not only by reference to his Fig. 30, but by measurement of our similar figure (Fig. 12) the coincidence of $U$ with the peak

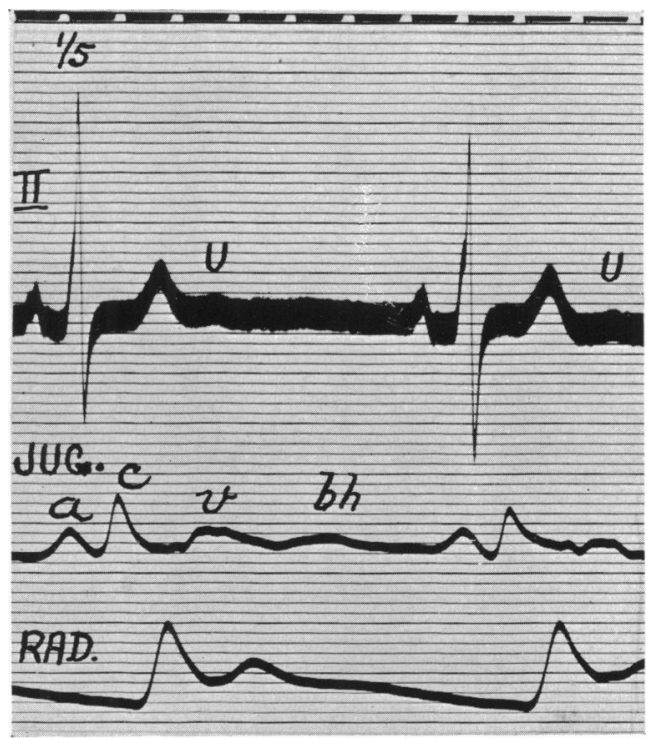

FIG. 12.-Combined electrocardiogram, jugular, and radial tracing. U coincides with the fall of " $v "$; and occurs long before the " $b \mathrm{~h}$ " wave.

or downstroke of " $v$ " can be established. Its appearance in the early stage of diastole, and its evident time relation with " $v$ " exclude any relation between $\mathrm{U}$ and the " $\mathrm{b} h$ " wave of the venous tracing which does not appear until late in diastole. It is found only in slowly acting hearts and is due to the floating up and transient closure of the tricuspid valves when the blood flows into the ventricle (Mackenzie, 1925). The first part of diastole has been termed by Luciani (1911) active diastole. Lewis (1925) refers to the second part of diastole, after the opening of the $\mathrm{A}-\mathrm{V}$ valves, as diastasis. Even assuming a remnant of muscular activity in the first part of diastole, i.e., the post-sphygmic period that is the interval between the closure of the semilunar and the opening of the A-V valves, this could not be represented by the $U$ wave ; for its appearance after the opening of the $A-V$ valves (the peak of the venous " $v$ " wave) rules out this explanation.

The simple fact of $U$ often beginning before the end of $T$, so as to deform it (Figs. 2 and 3), suggests at once that it can begin before systole is over, accepting the end of $T$ as the end of systolic contraction. In the $U$ wave we seem to have an electrical component, independent of both systole and diastole, arising sometimes before and sometimes after the end of T. Simultaneous records of 
the end of $T$ with a phonocardiogram of the second heart sound might help to decide, were $U$ waves present in such a combined record.

A certain similarity ketween the shape and direction of $T$ and $U$ and their similar response in experiment seem to suggest that they have a common origin, or at least that $U$ is derived in some way from the $T$ wave. Strongly against this explanation, however, is the common appearance of $U$ in bradycardia on the descending portion of T, i.e., before systole is over. As the end of $T$ marks the end of systolic contraction, $U$ might be a sequel of that contraction. Nahum and Hoff (1939) in this sense speak of $U$ as the expression of the phase of recovery, after the refractory period. If so, $U$ on this hypothesis should always have a direct time relation to $\mathrm{T}$ or to the end of $\mathrm{T}$. But the facts are to the contrary : $\mathrm{U}$ may as easily deform $\mathrm{T}$ as follow it, according to the simple factor of rate. The truth is that $U$ is related in time to QRS and not to $\mathrm{T}$. Once the Q-end $\mathrm{T}$ period is determined, a period which varies chiefly with rate, $U$ may be recognized as : (a) a hump on the downstroke of $T$, at a rate below 60, i.e., when the Q-end $\mathrm{T}$ period exceeds $0.40 \mathrm{sec}$. ; (b) an isolated wave, upright or inverted, at a normal or moderately high rate (60 to 110), i.e., when the Q-end $\mathrm{T}$ period is from 0.40 to $0.34 \mathrm{sec}$. ; (c) partially or totally fused with the succeeding $P$ at a rate above 110 , i.e., when the $Q$-end $T$ period is $0.34 \mathrm{sec}$. or less. The contrast lies between the relative fixity of the Q-U period, measuring $0.38-0.42 \mathrm{sec}$., and the variability of the $\mathrm{Q}-\mathrm{T}$ period measuring between 0.34 and $0.46 \mathrm{sec}$. at different heart rates. The idea that $U$ disappears with change of rate is incorrect. When it is not identified as a separate wave, it still may be present, fused with the succeeding $\mathrm{P}$ and elevating it correspondingly (Fig. 1).

Though existing hypotheses advanced to explain the $U$ wave have been criticized and even rejected, I am unable to offer anything more satisfactory. Its closer time relation with the QRS complex than with $\mathrm{T}$, and its beginning, sometimes before and sometimes after systole is completed, seem to exclude simple or direct relation to the muscular contraction of the heart. The $U$ wave may represent an electrical event in the heart muscle, so far novel and unrecognized, which is not the expression of a kinetic activity and so not directly related to the heart rate.

\section{SUMMARY}

Observations have been made on the incidence, appearance, and variations of the $U$ wave of the human electrocardiogram in health and disease ; and its genesis is discussed.

\section{The $U$ Wave in Health}

In about 70 per cent. of normal records $U$ is present in one or more limb leads, and in about 5 per cent. it is at least $0.5 \mathrm{~mm}$. in height. It is often larger in special chest leads, especially in IV $R$, in which it may be 0.25 to $2.0 \mathrm{~mm}$. high and 0.18 to 0.24 sec. in duration.

In tachycardia, it is fused with the succeeding P. In bradycardia with its lengthened S-T period, it overlaps T, forming a hump on its descending portion. 
It follows that $\mathrm{U}$ is related in time to $\mathrm{QRS}$ and not to $\mathrm{T}$; it tends to fuse with $\mathrm{T}$ when the $\mathrm{Q}-\mathrm{T}$ period is longer than $0.40 \mathrm{sec}$. It varies with respiration, becoming sharper and shorter in inspiration, and flatter and longer in expiration. It enlarges after exertion and in forced apnœa. Vagal release by atropin influences it little if at all ; vagal stimulation (e.g., by carotid sinus compression) may exaggerate or may dissipate the wave.

2. The $U$ Wave in Disease

Of 100 consecutive electrocardiograms in which $U$ was higher than $0.5 \mathrm{~mm}$. in limb leads, nearly half the patients had a blood pressure above $160 \mathrm{~mm}$. and 40 per cent. showed enlargement of the left ventricle on radioscopy. A large $U$ was less often seen with right ventricular enlargement. $U$ tends to be absent in heart failure and may first be seen during recovery from it. Digitalis can enlarge a small $U$ wave or produce one where none was seen before its administration. Though $\mathrm{T}$ and $\mathrm{U}$ may enlarge concurrently, there is otherwise little relation between them; for instance, a large $T$ may have a small $U$ wave following it or vice versa.

An inverted $U$ wave is the only pathological form yet recognized. It is to be found in coronary thrombosis, hypertension, angina pectoris, and aortic incompetence. Generally, it is found with an inverted $T$, though it can be the only pathological sign in an otherwise normal record.

After extrasystoles commonly, and in bundle branch block rarely, $U$ may be seen, either upright or inverted. Where $\mathrm{T}$ is bifid, as occasionally it is, the identification of $U$ may not be easy.

\section{Interpretation of the $U$ Wave}

The idea of its extracardiac origin is untenable. The $U$ wave is a product of cardiac contraction and has generally been held to occur after contraction has ceased, i.e., in diastole. At normal heart rates it appears early in diastole and coincides with the peak or the fall of the jugular " $v$ " wave, i.e., while the $\mathrm{A}-\mathrm{V}$ valves are open and therefore after systole is complete. It occurs well before the " $b h$ " venous wave. Yet as the $U$ wave in bradycardia begins before, and at a normal rate after the end of $\mathrm{T}$, and in tachycardia is fused with the succeeding $P, U$ may be envisaged not only as a more persistent wave than had been thought, but as an electrical event independent of both systole and diastole. The $R-U$ period is relatively constant while the $R-T$ period varies greatly with rate. This constant relation of $U$ to $R$, the lack of relation of $U$ to $T$, and the fact that a mere change in heart rate makes it seem at one time systolic and at another diastolic, render doubtful the interpretation of $U$ either as a wave arising from muscle going out of contraction or as the electrical expression of a supernormal recovery phase.

Possibly U has a hitherto unknown quality in that it appears unattached to systole or to diastole, for it is independent of $\mathrm{T}$ and also curiously independent of the heart rate.

I feel greatly indebted to Dr. John Parkinson, Physician to the Cardiac Department, who suggested and promoted these investigations ; without his constant help they could not have been completed. My thanks are also due to Dr. Evan Bedford for permission to use material from the Middlesex Hospital, and to Dr. A. N. Drury of Cambridge for his advice. 


\section{REFERENCES}

Blumberger, K. (1937). Z. klin. Med., 132, 478.

Boden, E. (1932). Die Elektrokardiographie für die ärztliche Praxis, Dresden.

Bramwell, C., and Ellis, R. (1931). Quart. J. Med., 24, 329.

Bruce, P. (1931). Arch. Dis. Childh., 6, 259.

Csinady, E. (1930). Arb. Physiol., 3, 579.

Einthoven, W. (1906-7). Arch. internat. Physiol., 4, 132.

- - (1912). Lancet, 1, 853.

Gross, K. (1934). Z. Kreislaufforschg., 26, 545.

Hering, H. E. (1913). Arch. die ges. Physiologie, 151, 111.

Herles, F. (1934). Casop. lék. česk., 73, 149.

Hinden, E. (1935). Lancet, 2, 1228.

Hoffmann, A. (1914). Die Elektrographie als Untersuchungsmethode des Herzens und ihre Ergebnisse, Wiesbaden.

Holzmann, M., and Wuhrmann, F. (1936). Dtsch. med. Wschr., 62, 379.

Hoogewerf, S. (1929). Ergebnisse der sportärztlichen Untersuchungen bei den ix. Olympischen Spielen in Amsterdam 1928, Berlin, p. 118.

Kahn, R. H. (1914). Erg. Physiol., 14, 1.

Krumbhaar, E. B., and Jenks, H. H. (1917). Heart, 6, 189.

Lewis, T. (1915). Phil. Trans. Roy. Soc., 205, 375.

- (1925). The Mechanism and Graphic Registration of the Heart Beat, London, p. 45. (1937). Clinical Electrocardiography, 6th ed., London.
and Gilder, M.D.D. (1912). Phil. Trans. Rov. Soc., 202, 351.

Lincoln, E. M., and Nicolson, G. H. B. (1928). Amer. J. Dis. Child., 35, 1001.

Luciani, L. (1911). Human Physiology, London, Vol. 1, 208.

Mackenzie, J. (1925). Diseases of the Heart, London.

Maekawa, M. (1931). Acta Sch. med. Univ. Kioto, 14, 16.

Nahum, L. D., and Hoff, H. E. (1939). Amer. Heart J., 17, 585.

Pardee, H. E. B. (1924). Clinical Aspects of the Electrocardiogram, 2nd ed., New York. (1933). Clinical Aspects of the Electrocardiogram, 3rd ed., New York.

Reid, W. D. (1928). The Heart in Modern Practice, Philadelphia, p. 49.

Schulz, W. (1938). Z. klin. Med., 136, 2.

Seham, M. (1921). Amer. J. Dis. Child., 21, 246.

Spang, K., and Korth, C. (1939). Arch. Kreislaufforschg., 4, 257.

Székely, P. (1938). Casop. lek. česk., 77, 1049.

Trendelenburg, W. (1933). Z. ges. exper. Med., 92, 30.

Tung, Chen-Lang (1936). Amer. Heart J., 2, 89.

Weber, A. (1926). Die Elektrokardiographie, Berlin.

Wenckebach, K. F., and Winterberg, H. (1927). Die Unregelmässige Herztätigkeit, Leipzig.

White, P. D. (1937). Heart Disease, 2nd ed., New York, p. 143.

Wiggers, C. J. (1923). Circulation in Health and Dis zase, 2nd ed., Philadelphia, p. 285.

Wolff, L., Parkinson, J., and White, P. D. (1930). Amer. Heart J., 6, 685.

Wood, P., and Selzer, A. (1939). Brit. Heart J., 1, 49. 